\title{
Electricity Generation and Biofilm Formation in Microbial Fuel Cells Using Plate Anodes Constructed from Various Grades of Graphite
}

\author{
Wudneh Ayele Shewa ${ }^{1 *}$, Subba Rao Chaganti ${ }^{2}$ \\ and Jerald A. Lalman ${ }^{1}$ \\ ${ }^{1}$ Department of Civil and Environmental Engineering, University of Windsor, \\ Center for Engineering Innovation, 401 Sunset Ave., Windsor, ON, Canada, \\ N9B 3P4, (*Corresponding Author: shewa@ uwindsor.ca) \\ ${ }^{2}$ Great Lakes Institute for Environmental Research, University of Windsor, \\ 401 Sunset Ave., Windsor, ON, Canada N9B 3P4
}

Received: January 23, 2014; Accepted: February 19, 2014

Publication: May 8, 2014

\begin{abstract}
Construction materials as well as the electrode configuration are major factors affecting electricity generation in microbial fuel cells (MFCs). Three graphite plate electrodes (HK06, G347 and POCO3) with different characteristics (specific resistance, grain size and specific gravity) were used to evaluate electricity generation and biofilm formation in MFCs. The electrodes were assessed by operating duplicate MFCs under the same conditions. Electrochemical impedance spectroscopy, cyclic voltammetry and linear sweep voltammetry were used to evaluate the performance of the electrodes. The data indicated the grade of electrode played a critical role in the MFCs performance. Higher power density was observed for the graphite electrode designated as POCO3. The trend for increasing electricity generation was as follows: POCO3 > G347 > HK06. Distinct microbial populations were detected in the biofilm community when comparing the different electrodes. Selecting electrodes for optimum electricity generation is important in the development of laboratory scale and full-scale MFCs.
\end{abstract}

Journal of Green Engineering, Vol. 4, 13-32.

doi: 10.13052/jge1904-4720.412

(c) 2014 River Publishers. All rights reserved. 
Keywords: Microbial fuel cell, Graphite plate electrode, Energy efficiency, biofilm, Performance comparison.

\section{Introduction}

Depleting fossil fuel resources, environmental damage and energy security are key factors driving the search for renewable energy supplies. Microbial fuel cell (MFC) is a promising alternative to produce a renewable energy source from organic matter. MFCs have many operational and functional advantages over technologies currently used for generating energy from organic matter (Rabaey and Verstraete, 2005). According to Rabaey and Verstraete (2005), these advantages include the following: high conversion efficiency is achieved by the conversion of substrate energy to electricity, efficient operation at ambient and at low temperatures distinguishes them from current bio-energy processes, gas treatment is not required because the off-gases from MFCs are enriched in carbon dioxide, energy input is not required for aeration provided the cathode is passively aerated and potential application in area lacking electrical infrastructure.

MFCs represent a potential alternative approach when compared to conventional activated sludge wastewater treatment systems because energy is produced in the form of electricity or hydrogen gas rather than using energy for aeration or for other treatment processes (Logan, 2008). The application of MFCs for wastewater treatment has been documented in many reports (Aelterman et al., 2006; Ahn and Logan, 2010; Cha et al., 2009; Kargi and Eker, 2007; Vidris et al., 2008).

In its most simple configuration, an MFC is a device which uses microorganisms to produce an electrical current. The oxidation of organic chemicals by microorganisms liberates both electrons and protons. Electrons are then transferred from microorganisms to the anode and then subsequently to the cathode through an electrical network. Simultaneously, protons (electron acceptor) migrating to the cathode combine with electrons and an electron acceptor such as oxygen to produce water. The electrical current generated is similar to that in chemical fuel cells; however, in MFCs microbial catalysts are attached to the anode surface (Franks and Nevin, 2010).

MFCs are configured in a variety of configurations. Single chamber MFCs are designed with an anodic compartment without the requirement for an aerated compartment containing cathode. In a typical configuration, the anode contained in a compartment is coupled with a porous air-cathode (Liu et al., 2005, Park and Zeikus, 2003). In a two chamber MFC configuration, 
the oxidation of the electron donors on an anode is physically separated from the reduction of an electron acceptor on the cathode. Microorganisms are cultivated on the anode where electron donors are oxidized. Electrons are transferred to the anode and subsequently to oxygen or other electron acceptors. Typically, the anode compartment is separated from the cathode compartment by a proton exchange membrane (PEM) or cation exchange membrane (CEM).

The performance and cost of electrodes are important factors affecting the design of MFCs (Wei et al., 2011). A wide range of electrode materials and configurations have been examined in recent years to improve the performance and reduce cost. A suitable electrode must be a good conductor, chemically stable, mechanically strong and not expensive (Wei et al., 2011).

Identifying materials and architectures which maximize power generation and coulombic efficiency is a major challenge in designing MFCs (Logan, 2008). Another challenge is to reduce cost and develop configurations which can be constructed from a practical point-of-view (Logan, 2008). According to Logan and Regan (2006), the most significant impediment in achieving high power densities in MFCs is the system configurations and not the composition of the bacterial community.

Utilizing electrodes with improved properties will enhance the performance of MFCs because different anode materials result in different activation polarization losses (Du et al. 2007). Because the power output of MFCs is low relative to other type of fuel cells, reducing their cost is essential if power generation using this technology is to be an economical method of energy production (Liu and Logan, 2004). Many studies have focused on maximizing the power generation in MFCs; however, work on cost minimization studies is limited. Practical applications of MFCs will require developing designs that will not only produce high power outputs and coulombic efficiencies but also economical to manufacture in large quantities (Logan, 2008). In this study, the cost of the material was also considered in the evaluation of different electrode materials. An improved understanding of the type together with the selection of cost effective electrodes for MFC is important. In spite of many published studies which have focused on power generation and coulombic efficiency of MFCs; no study has considered electrode cost when evaluating their performance. Hence, the objective of this study was to assess the significance of cost for different graphite plate electrode on the performance of MFCs. 


\section{Material and Methods}

\subsection{Microbial Fuel Cell Set-up and Operation}

The air-cathode single chamber microbial fuel cell (SCMFC) used in this study is depicted in Figure 1. The air-cathode was constructed as previously described by Cheng et al. (2006). The air-cathode was constructed with $2.5 \mathrm{mg} / \mathrm{cm}^{2}$ platinum on the inner surface facing the media solution. The outer surface of cathode was coated with four layers of polytetrafluoroethane (PTFE) to prevent water loss and substrate oxidation by oxygen. The anodes used were graphite plate electrodes with a surface area of $25.6 \mathrm{~cm}^{2}$. The fuel cell working volume was $130 \mathrm{~mL}$. The SCMFCs were operated in batch mode and fed with fresh medium (described in section 2.2) after 6 to 7 days or when the voltage decreased to below $20 \pm 5 \mathrm{mV}$. All the experiments were conducted in triplicate.

Two chamber MFCs (Figure 2) were constructed with two cylindrical chambers connected by a polyethylene tube. The flanged tubes were fitted with porous inserts to accommodate a proton exchange membrane (PEM) (Nafion 117, Fuel Cell Earth LLC). The total volume of each chamber was 2 litres. The PEM was pre-treated to remove impurities before placing it between the flanges. The pre-treatment process was as follows: dipped in a boiling 30\% $\mathrm{H}_{2} \mathrm{O}_{2}$ solution, washed with deionized water, dipped in $0.5 \mathrm{M} \mathrm{H}_{2} \mathrm{SO}_{4}$, and washed with deionized water (60 mins for each step).

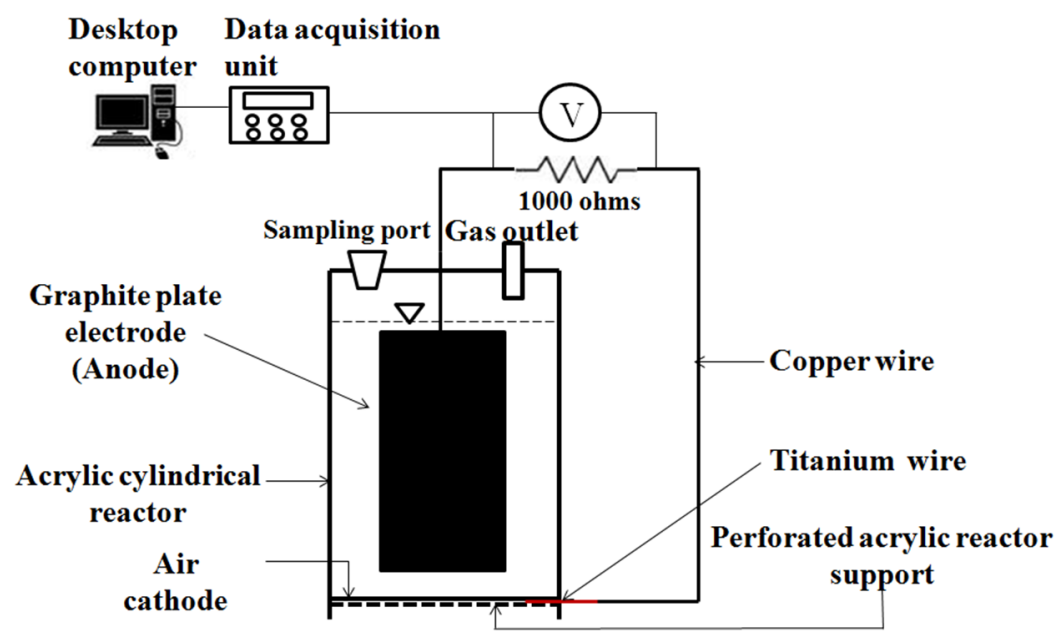

Figure 1 Schematic of a single chamber MFC 


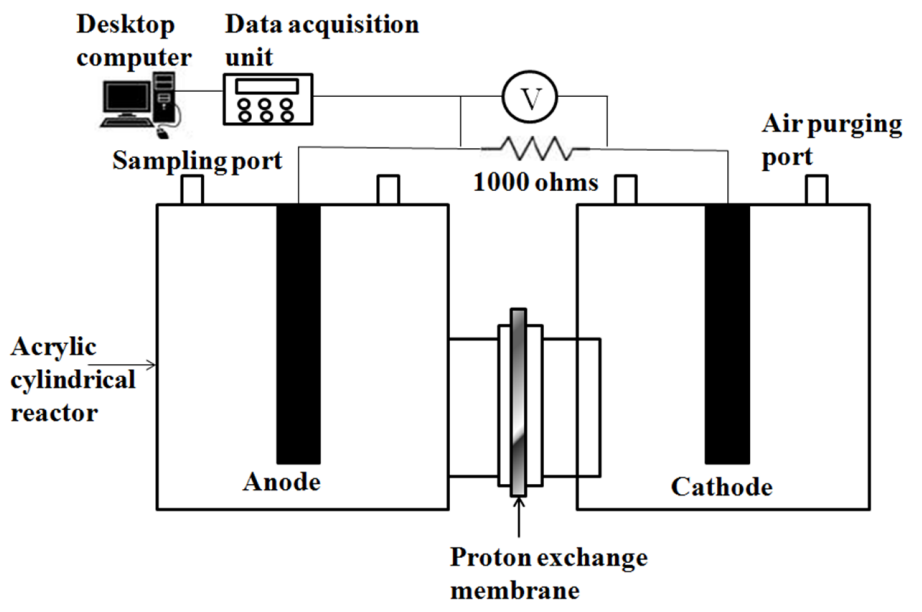

Figure 2 Schematic of a two chamber MFC

All the MFCS were operated at $21 \pm 1^{\circ} \mathrm{C}$ with the same inoculum, substrate concentration and external load (1,000 ohm).

\subsection{Inoculums Source and Medium}

In this study, the SCMFCs and the two chamber MFCs were seeded with a mixed anaerobic culture which was obtained from a municipal wastewater treatment facility (Chatham, ON). The medium added to the SCMFCs and the anodic chamber of the two chamber MFCs contained the following: $500 \mathrm{mg} \mathrm{L}^{-1}$ glucose, $310 \mathrm{mg} \mathrm{L}^{-1} \mathrm{NH}_{4} \mathrm{Cl}, 130 \mathrm{mg} \mathrm{L}^{-1} \mathrm{KCl}, 4225 \mathrm{mg} \mathrm{L}^{-1}$ $\mathrm{NaH}_{2} \mathrm{PO}_{4} . \mathrm{H}_{2} \mathrm{O}, 7400 \mathrm{mg} \mathrm{L}^{-1} \mathrm{Na}_{2} \mathrm{HPO}_{4} .12 \mathrm{H}_{2} \mathrm{O}, 10 \mathrm{mg} \mathrm{L}^{-1}$ yeast extract and $1 \mathrm{~mL} \mathrm{~L}^{-1}$ of a mineral solution. The mineral solution was prepared in accordance with the procedure described by Wiegant and Lettinga (1985). The solution for the cathode chamber of the two chamber MFCs contains all the constituents mentioned above except glucose and yeast extract. The cathodic chambers of the two camber MFCs were continuously purged with air to provide oxygen in solution.

\subsection{Electrodes}

In this study, the configuration of the three graphite plate electrodes (POCO3, HK06 and G347) (MWI Inc, Rochester, NY) are shown in Figure 3. Specifications for the electrodes are shown in Table 1. The electrodes were washed with deionized water before placing them in the MFCs. 


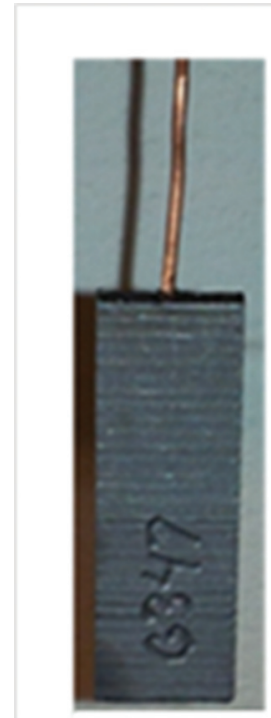

A

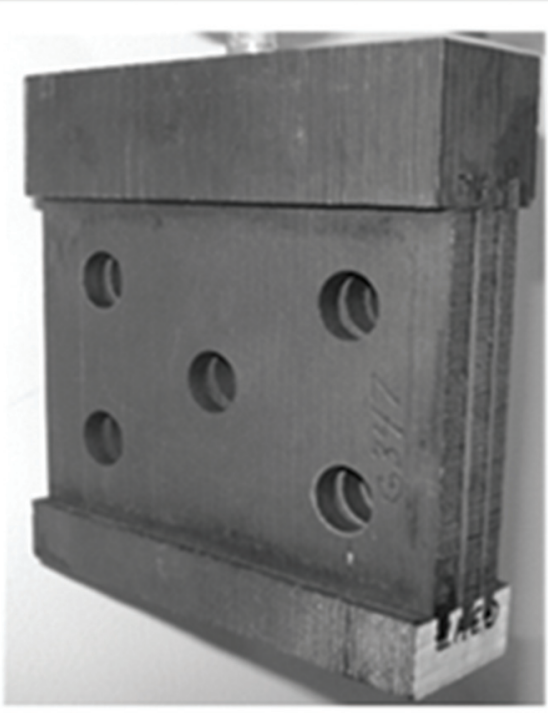

B

Figure 3 Electrode design used in the MFC experiments A) Single chamber electrode; B) Two chamber electrode

Table 1 Properties of graphite plate electrodes

\begin{tabular}{llccc}
\hline & & \multicolumn{3}{c}{ Grade of Electrode } \\
\cline { 3 - 5 } Description & Unit & POCO3 & HK06 & G347 \\
\hline Specific Gravity & - & 1.81 & 1.86 & 1.85 \\
Specific Resistance & $\mathrm{mWm}$ & 14 & 12 & 11 \\
Flexural Strength & $\mathrm{MPa}$ & 93 & 85 & 49 \\
Shore Hardness & $\mathrm{Shore}$ & 76 & 68 & 58 \\
Average grain size & $\mathrm{mm}$ & $<5$ & 3 & $\mathrm{NA}$ \\
\hline
\end{tabular}

\subsection{Data Acquisition and Analysis}

Cell voltages (V) of each MFC were sampled every 5 min using an Agilent 34970A data acquisition unit connected to a computer. A full channel scan was performed for all MFCs and the data was stored for analysis. The potential of the anode and cathode electrodes was measured versus an $\mathrm{Ag} / \mathrm{AgCl}$ reference electrode ( $\mathrm{CH}$ instruments Inc., Austin, TX) with the anode or the cathode as the working electrode.

Cyclic voltammetry was employed to acquire qualitative data related to electrochemical reactions and to locate redox potentials of the electroactive 
species. Electrochemical impedance spectroscopy (EIS) was used to determine the internal resisitance of the SCMFCs. The polarization and power density curves for SCMFCs were obtained using linear swipe voltammetry (LSV). Two chamber MFCs were characterised using different external resistances $(1,000,000,10,000,5,600,1,000,680,470,330,220,100,47,8.2$ and $1.5 \Omega$ ), with each resistance being connected for $15 \mathrm{~min}$. The potential $(V)$ was used to calculate the current $(I)$. The power density, $\mathrm{P}\left(\mathrm{mW} / \mathrm{m}^{2}\right)$, was calculated using the surface area $(A)$ of the anode $(P=I \times V / A)$. The power was also normalized based on working volume to express the power density in $\mathrm{mW} / \mathrm{m}^{3}$.

The coulombic efficiency $\left(C_{E}\right)$ and the energy efficiency $\left(\eta_{M F C}\right)$ were calculated using equations 1 and 2 (Logan, 2008).

$$
C_{E}=\frac{M_{s} \int_{0}^{t_{b}} I d t}{F b_{e s} \nu_{A n} \Delta c}
$$

$M_{s}$ is the molecular weight of the substrate, $t_{b}$ is time for one feeding cycle, $F$ is Faraday's constant, $b_{e s}$ is number of moles of electrons per mole of substrate, $v_{A n}$ is the volume of liquid in the anode compartment and $\Delta c$ is the substrate concentration change over a feeding cycle.

$$
\eta_{M F C}=\frac{\int_{0}^{t_{b}} E_{M F C} I d t}{\Delta H n_{s}}
$$

Where $E_{M F C}$ is the voltage, $\Delta H$ is the heat of combustion and $n_{s}$ is the amount (mol) of substrate added.

A principal component analysis (PCA) was employed to correlate the material characteristics and the electrode efficiencies.

\subsection{Analytical Methods}

Liquid samples $(5 \mathrm{ml})$ were withdrawn from the MFCs after initiation of the experiment and at the end of every feeding cycle. These samples were filtered using a $0.45 \mu \mathrm{m}$ polypropylene membrane (GE Osmonics, MN) and a 100 to 200 mesh ion exchange resin (Chelex 100, Bio-Rad, CA) to remove heavy metals and suspended solids. The filtered samples were analyzed for COD according to Standard Methods (APHA, 2005).

Microbial samples were removed from the liquid suspension in the anodic chamber and from the anode surface upon completing the last feeding cycle. DNA isolation, polymerase chain reaction (PCR) and terminal restriction fragment length polymorphism (T-RFLP) profiling of the microbial community 
samples were performed in accordance with methods described by Chaganti et al. (2012).

\section{Results and Discussions}

\subsection{Comparative Power Production}

The MFCs were operated under batch conditions with each feeding cycle 6 to 7 days and the number of batch feeding cycles was 10. The feeding period was variable depending on the voltage reduction to a low value of $20 \pm 5 \mathrm{mV}$. After seeding the MFCs, steady-state voltages were observed at the end of 6 feeding cycles (approximately 6 weeks). Variation in the cell potential with time in the two chamber MFCs configured with three different grades of graphite is shown in Figure 4. Variation in the voltage pattern was observed as follows: POCO3 > G347 > HK06. The cell potential under different loads is shown in Figure 5 and a distinct difference is observed in this case. A similar trend (POCO3 > G347 > HK06) was also observed for the SCMFCs voltage generation (data not shown).

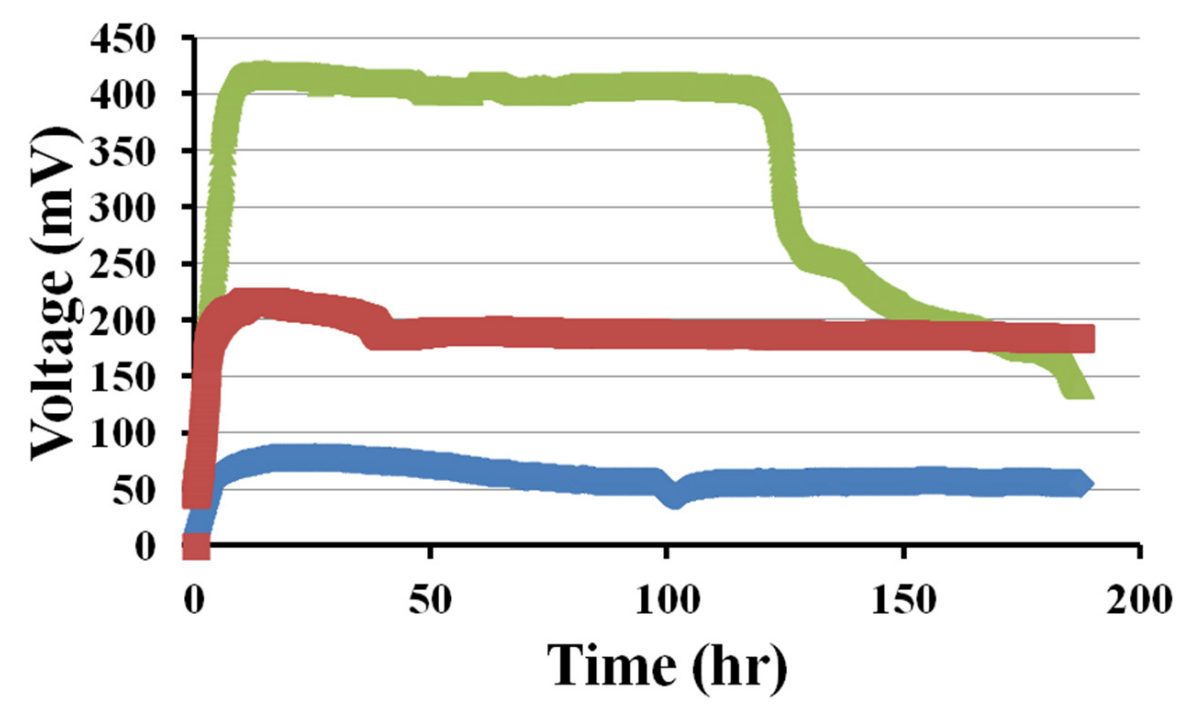

\section{$\triangle$ POCO 3 HKO6 $\square$ G347}

Figure 4 Representative one batch feeding cycle voltage generation in the two chamber MFCs configured with three different graphite electrodes

Note: The MFCs were operated under a constant external load of $1000 \mathrm{ohms}$ 


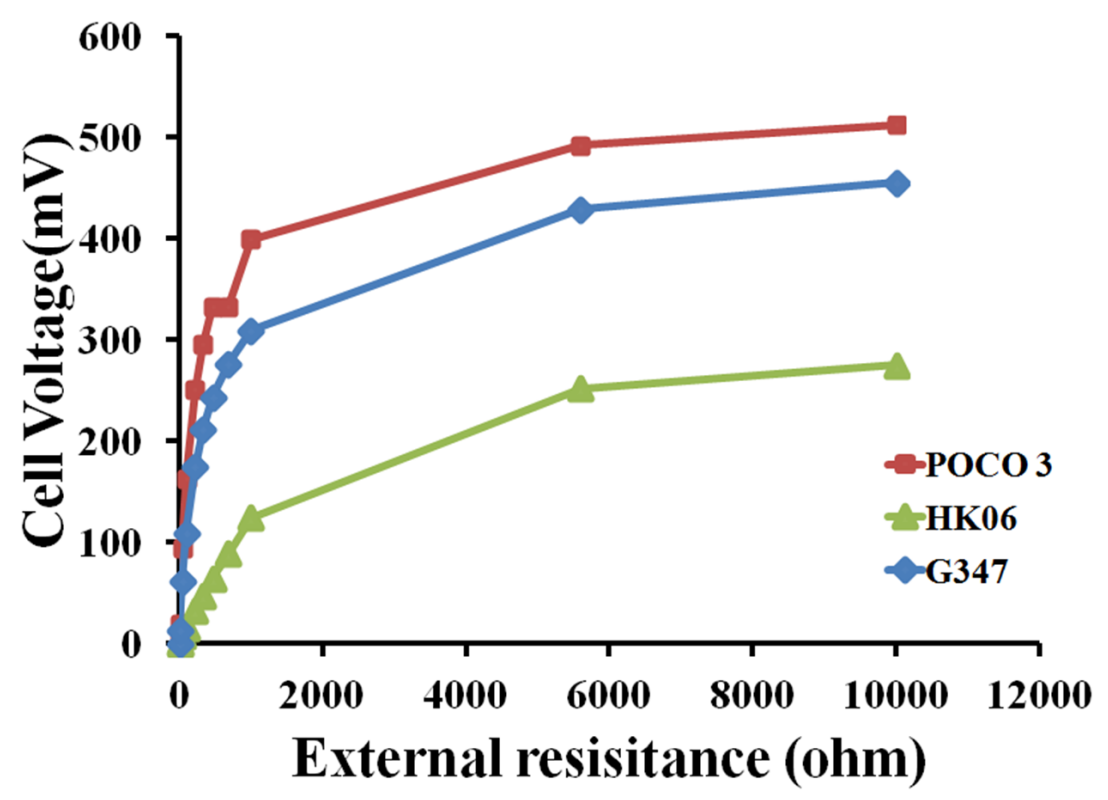

Figure 5 Cell potential in the two chamber MFCs configured with three different graphite electrodes and under varying external loads

\subsection{Current - Power Profile}

\subsubsection{Single chamber MFCs}

Many researchers use different units to denote the performance of an MFC. Current density, a common unit, is either represented as the current generated per unit area of the anode surface area $\left(\mathrm{mA} / \mathrm{cm}^{2}\right)$ or current generated per unit volume of the cell $\left(\mathrm{mA} / \mathrm{m}^{3}\right)$ (Pant et al., 2010). According to Logan (2012), it is appropriate to normalize power to the membrane or cathode surface area. In this study, the current and power densities are reported as per unit area of the anode surface area, per unit of area of the air cathode and per unit volume of the cell (Table 2).

The maximum power density for the MFCs using the linear swipe voltammetry (Figure 6) was obtained by varying the potential of the working electrode at a scan rate of $1 \mathrm{mV} \mathrm{s}^{-1}$. This data show that the POCO3 material produced $1078 \mathrm{~mW} / \mathrm{m}^{2}\left(2682 \mathrm{~mW} / \mathrm{m}^{3}\right)$ which is approximately twice larger than that of the $\mathrm{G} 347$ material $\left(520 \mathrm{~mW} / \mathrm{m}^{2} ; 1473 \mathrm{~mW} / \mathrm{m}^{3}\right)$ and 10 times larger than that of the HK06 material $\left(102 \mathrm{~mW} / \mathrm{m}^{2} ; 282 \mathrm{~mW} / \mathrm{m}^{3}\right)$ (Table 2). This indicates that POCO3 has the highest current density followed by G347 and HK06. 
22 Wudneh Ayele Shewa et al.

Table 2 Maximum current and power density of SCMFCs provided with different plate electrodes

\begin{tabular}{lllllll}
\hline & \multicolumn{2}{c}{$\begin{array}{c}\text { Normalized to } \\
\text { Working Volume }\end{array}$} & \multicolumn{2}{c}{$\begin{array}{c}\text { Normalized to } \\
\text { Cathode Surface Area }\end{array}$} & \multicolumn{2}{c}{$\begin{array}{c}\text { Normalized to Area } \\
\text { Anode Surface Area }\end{array}$} \\
\cline { 2 - 7 } Grade of & $\mathrm{I}$ & $\mathrm{P}$ & $\mathrm{I}$ & $\mathrm{P}$ & $\mathrm{I}$ & $\mathrm{P}$ \\
Electrode & $\left(\mathrm{mA} / \mathrm{m}^{3}\right)$ & $\left(\mathrm{mW} / \mathrm{m}^{3}\right)$ & $\left(\mathrm{mA} / \mathrm{m}^{2}\right)$ & $\left(\mathrm{mW} / \mathrm{m}^{2}\right)$ & $\left(\mathrm{mA} / \mathrm{m}^{2}\right)$ & $\left(\mathrm{mW} / \mathrm{m}^{2}\right)$ \\
\hline POCO3 & 8144 & 2682 & 1078 & 355 & 414 & 136 \\
HK06 & 769 & 282 & 102 & 37 & 39 & 14 \\
G347 & 3929 & 1473 & 520 & 195 & 200 & 75 \\
\hline
\end{tabular}

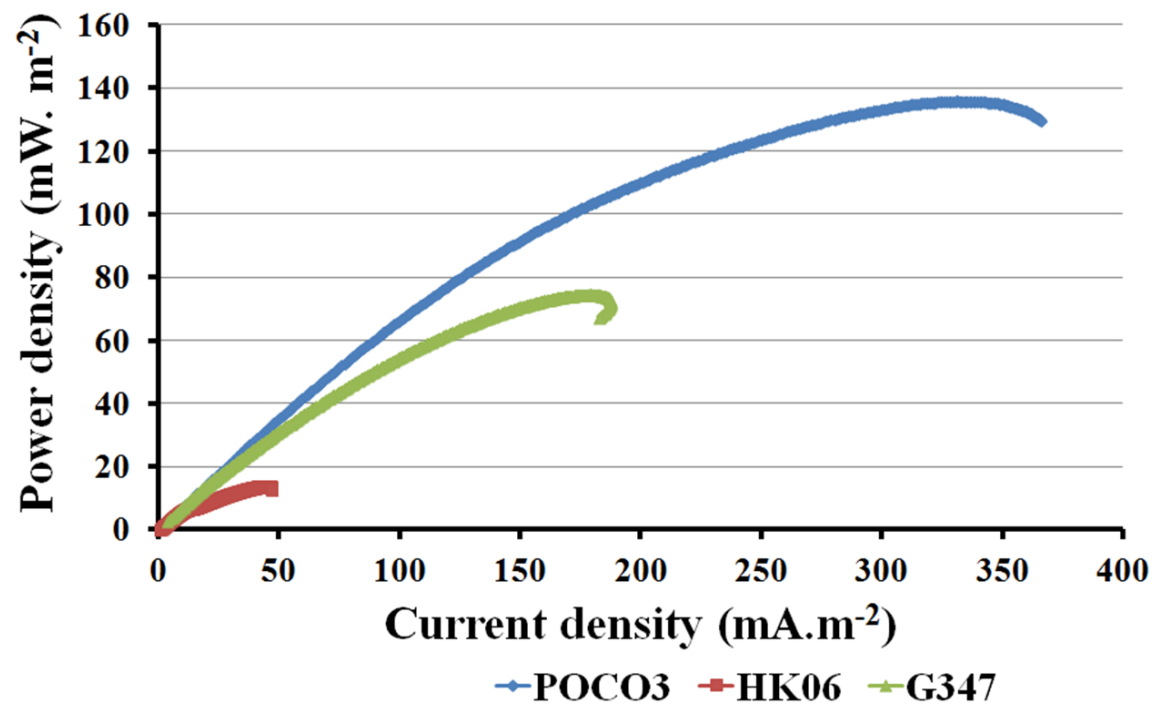

Figure 6 power density curves normalized to electrode surface area as a function of current density for SCMFCs

\subsubsection{Two chamber MFCs}

The current and power densities trend for the two chamber system was similar as that observed for the single chamber MFC configuration (POCO3 > G347 > HK06). The current and power profiles for the three electrodes are depicted in Figure 7. The low power density observed is attributed to the large distance between the cathode and anode electrodes, membrane resistance and the solution conductivity. Another reason is low surface area of the anode compared to the volume of the anolyte (Ringeisen et al., 2006). The two chamber MFC was also not operated under strict anaerobic condition because 


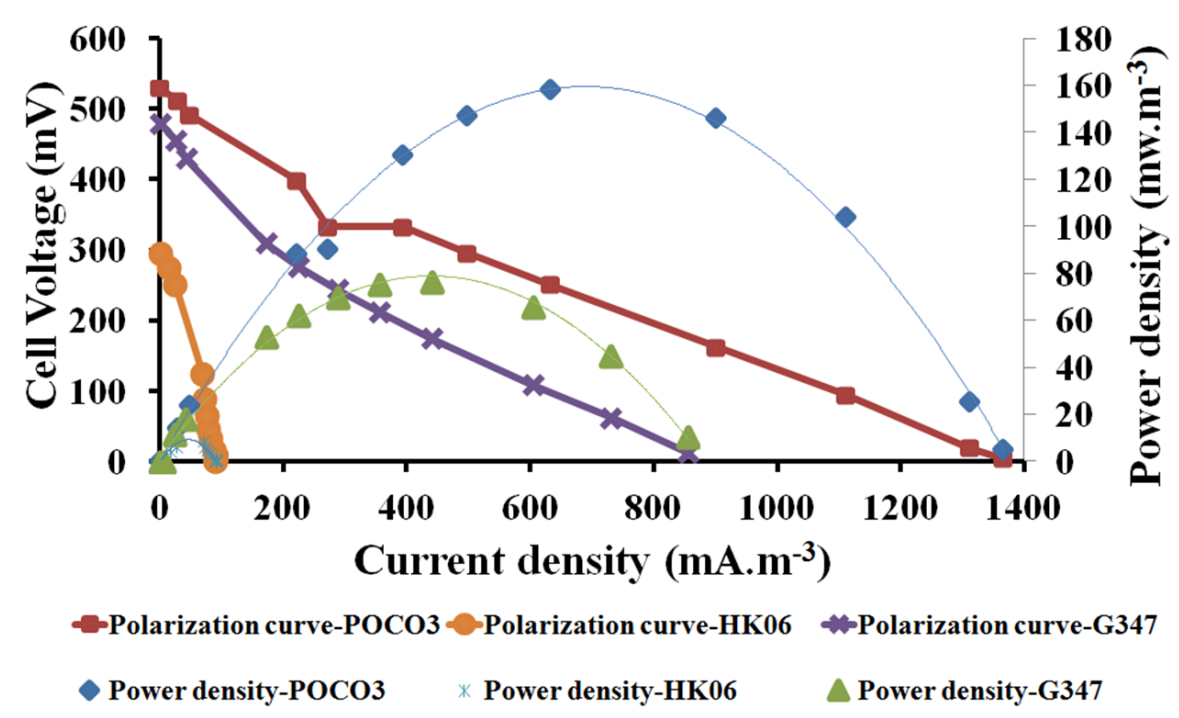

Figure 7 Polarization and power density curves normalized to the electrode surface area as a function of current density for the two chamber MFC

the sampling port (which was also used as a vent) was open throughout the entire operation of the MFCs. Therefore, the operating condition was facultative and this may be another reason for the lower power density production. However, note the lower power production would likely have no effect in comparing the electrodes performance since, the operating conditions for the MFCs are the same. The results show differences in the electricity generation of the different electrodes (Figure 7).

\subsection{Comparison of MFC Efficiencies}

The coulombic efficiency, energy efficiency and COD removal efficiency for SCMFCs configured with different anode materials are shown in Table 3. Notice the HK06 efficiency is very low when compared to POCO 3 and G347. The POCO 3 and G347 materials did not shown significant variation in efficiency. The low $(<12 \%)$ coulombic and energy efficiencies for the three electrodes were likely due to the conversion of glucose into volatile fatty acids such as acetate, butyrate, and propionate. Rahimnejad et al. (2011) reported similar results and according to Logan (2008) the energy efficiency values for MFCs range from $2 \%$ to $50 \%$ for easily biodegradable substrates. 
Table 3 Efficiency of SCMFCs provided with different electrodes

\begin{tabular}{llll}
\hline Grade of & Coulombic & Energy & COD \\
Electrode & Efficiency $(\%)$ & Efficiency $(\%)$ & Removal $(\%)$ \\
\hline POCO3 & 10.97 & 2.09 & 91.3 \\
HK06 & 2.53 & 0.11 & 25.94 \\
G347 & 11.79 & 1.72 & 84.63 \\
\hline
\end{tabular}

\subsection{Cost Effectiveness}

MFCs with POCO3 electrodes had the highest electricity generating capacity compared to G347 and HK06. However, when comparing the price of the electrode (anode only) per reactor, the G347 material cost was less. Based on the two chamber MFC configuration (Figure 2) and electrode design (Figure 3B), the cost of electrode (anode) is $\$ 9.45$ per reactor where as the costs for the other two electrodes POCO3 and HK06 are \$124.86 and \$39.21, respectively. The cost includes not only cost of material but also cost of cutting and fixing the electrodes as per the design indicated in Figure 3B.

To identify the most cost effective electrode, the cost of the electrode per reactor was divided by the maximum power density. The results show that the lowest cost of $\$ 0.12$ for a power output of $1 \mathrm{~mW} \cdot \mathrm{m}^{-3}$ per one feeding cycle was obtained for G347 while the cost for POCO3 and HK06 were \$1.26 and $\$ 4.29$, respectively. Therefore, among the different graphite plate electrodes, G347 was the most cost effective electrode followed by POCO3 and HK06. The G347 electrode also had the lowest specific resistance (Table 1) when compared to that of POCO3 and HK06 electrodes. The lowest cost and the lower specific resistance can be attributed to the cost effectiveness of the G347 material. This indicates that the costs of the two electrodes POCO3 and HK06 are high for practical applications. Therefore, G347 is the best material for MFCs based on large scale applications. Among the different electrode materials, POCO3 is the best candidate for MFCs if the choice is based only on current or power production. However, when electrode cost is considered in addition, to the electricity production capacity, the G347 material is the most cost effective option.

\subsection{Microbial Growth and Electricity Generation}

The physico-chemical characteristics of different electrode materials can affect the microbial colonization of surfaces (Sun et al., 2011). Variation in microbial populations was observed in the three electrodes under examination. The POCO3 electrode was more suitable for the growth of electrochemically 
active bacteria when compared to the G347 and HK06 materials. In addition to the power density results, the microbial analysis revealed that different microbial populations were detected in the biofilms developed on the surface of the different materials (Figure 8). On the POCO3 and G347 materials, similar band patterns were detected irrespective of the band intensities. However, in case of the HK06 material, the band pattern was different when compared to the POCO3 and G347 materials. The T-RFs data was further analysed for the identification of the different organisms (Chaganti et al., 2012). The results showed that Geobacter sp., Brucella sp., and Fusobacterium sp., were dominant on the POCO3 and G347 surfaces, whereas the relative abundance of the same bands was low in case of HK06.

Generally, the power generation capacity is related to the biofilm formed on anodes as microbes adhere to their surface (Rabaey and Rozendal, 2010). Previous studies have reported detecting Geobacter sp. in MFC biofilms (Lovley et al., 2011; Bond and Lovley 2003). Brucella sp. and Fusobacterium sp. are also capable of biofilm formation; however, these microorganisms have not been reported to participate in bioelectricity production (Almiron et al., 2013; Chew et al., 2012). The abundance of Geobacter sp. in $\mathrm{POCO} 3$ is associated with greater power generation curves. In case of the HK06 material, the dominant band was uncultured bacteria. The results from this study clearly indicate that biofilm formation is dependent on the quality of the graphite material composition.

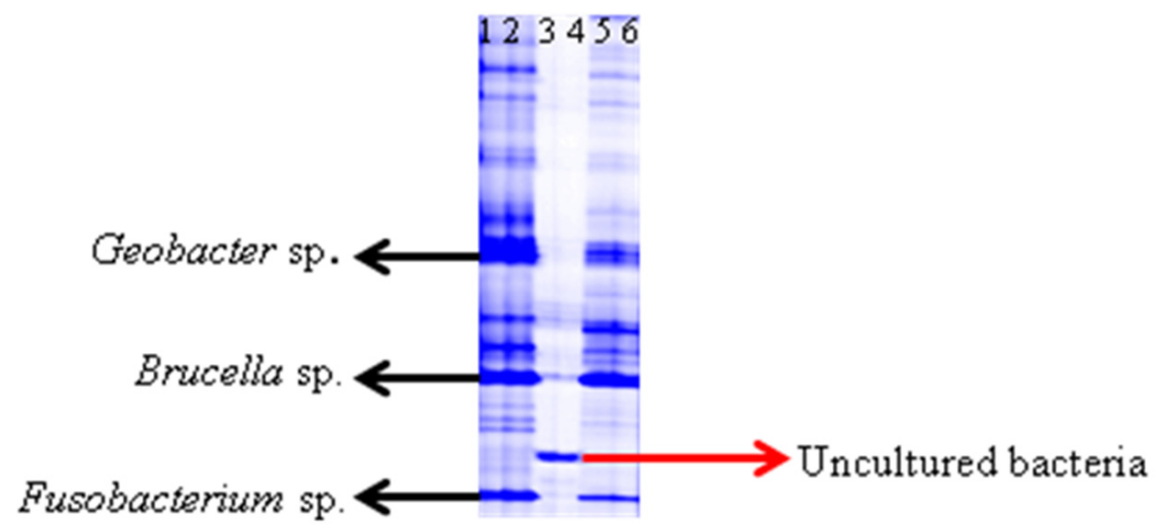

Figure 8 Microbial characterization of biofilms on different graphite anodes. Lane 1 and 2 = POCO3; lane 3 and $4=\mathrm{HK} 06$; lane 5 and $6=\mathrm{G} 347$ 


\subsection{Cyclic Voltammograms}

Cyclic voltammetry (CV) was performed to characterize the catalytic properties of the microbial populations in biofilm on the electrodes. The potential scan from $-0.4 \mathrm{~V}$ to $+0.4 \mathrm{~V}$ was performed at a scan rate of $1 \mathrm{mV} / \mathrm{s}$. The cyclic voltammograms (Figure 9) show the presence of redox peaks for the different electrodes. A higher redox peak observed for POCO3 (Figure 9) compared to the other electrodes indicate that $\mathrm{POCO} 3$ is very effective in the formation of a microbial film. In case of the POCO3 and G347 materials, the multiple redox peaks suggest that more than one microorganism participated in electricity production. To some extent, the $\mathrm{CV}$ data correlated with the result from the microbial analysis (section 3.5).

\subsection{Principal Component Analysis}

Principle components (PCs) are linear combinations of the measured variables. The PCA bi-plots indicate that the electrodes are different from each another and it also shows an association between the material properties and the MFCs performance variables and the electrodes (Figure 10). The PCA showed two PCs. The first PC explained $64.15 \%$ of the variance and the second PC explained $35.85 \%$ of the variance in the data set (Figure 10). The PCA also

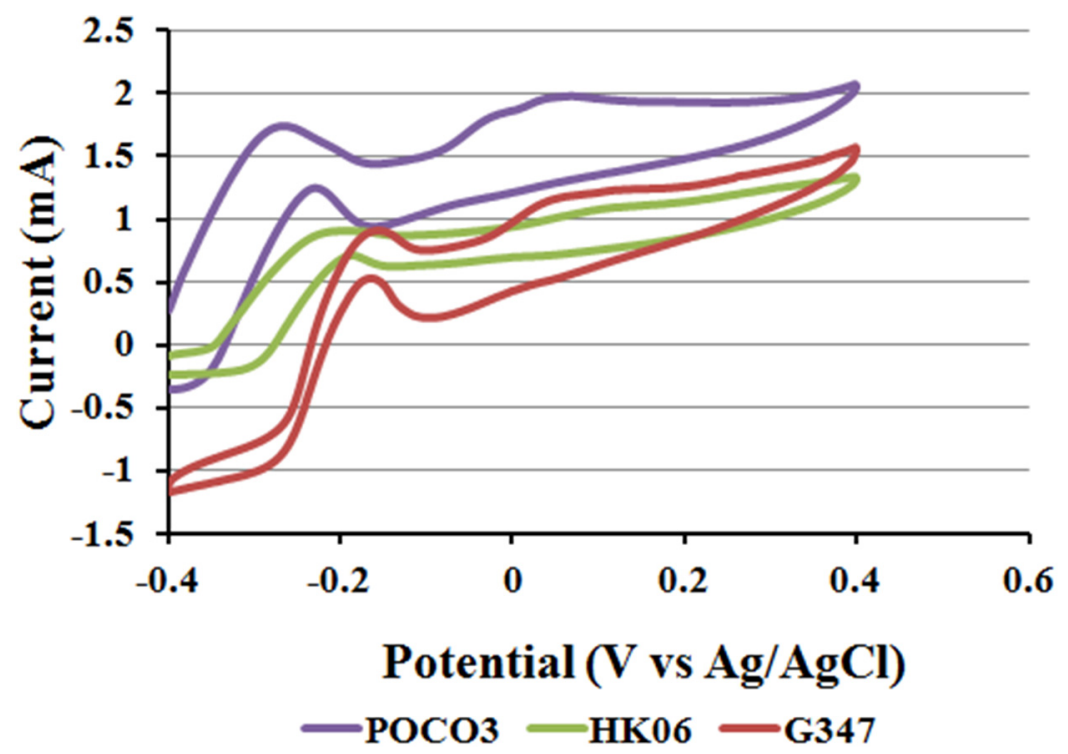

Figure 9 Cyclic voltammogram of bacterial biofilm on SCMFC graphite plate electrodes 


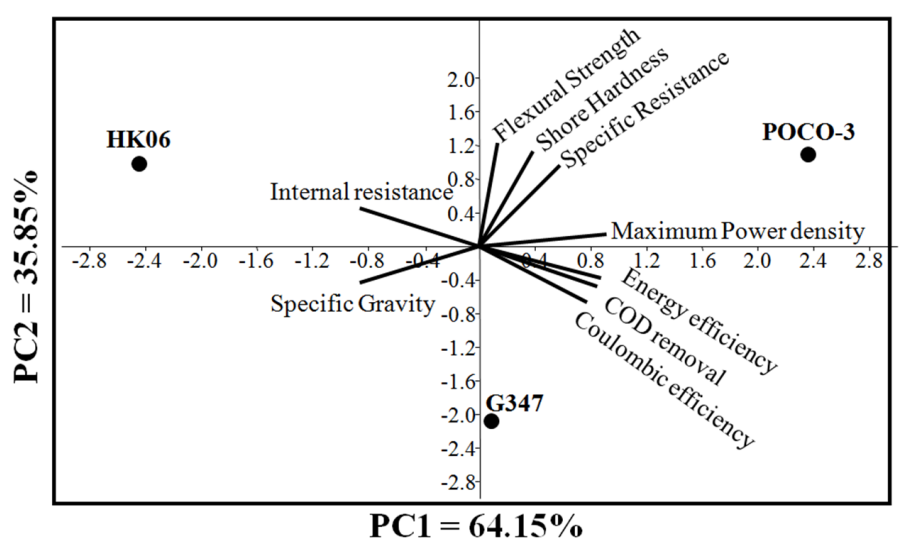

Figure 10 Principal component analysis of graphite plate electrodes properties and efficiencies

highlights similarities and differences between the three electrodes. The length of each vector indicates the dominance of the various factors. In this case, none of the factors were dominant. Principal components 1 and 2 combined explained $100 \%$ of the variance in the data set. According to Varmuza and Filzmose (2009), if the objects points are positioned in a plane, PC1 and PC2 is able represent the data structure. These authors also state that the sum of the variances preserved by $\mathrm{PC} 1$ and $\mathrm{PC} 2$ is close to $100 \%$.

Energy efficiency, COD removal, coulombic efficiency and maximum power density are positively correlated with $\mathrm{PC} 1$ while the internal resistance and specific gravity are negatively correlated with PC1. The flexural strength and shore hardness were correlated with PC2. Vectors in the same direction reinforce their effect, those at $90^{\circ}$ are independent and when placed in the opposite direction, they work against each other. In this study, the coulombic efficiency is negatively affected by the internal resistance and notice the energy efficiency is correlated with COD removal.

\section{Conclusion}

The performance of different graphite plate anode materials in single and double chamber MFCs was detected in this study. The selection of electrode material is essential in the design of MFCs. This research contributes to the advancement of MFCs since it provides tools for selecting suitable anode graphite materials to construct laboratory scale MFCs. Of the three graphite electrodes, the best grade was selected based on power generation, biofilm 
formation and cost. This study has clearly indicated the variation in the electricity generation and biofilm formation using different grades of graphite plate electrode. The findings have significant impact in understanding the performance of electrode material and depicted relevant parameters required for comparison. The conclusions from this study are as follows:

1. Electricity generation and microbial biofilm communities on anodes are affected by the physio-chemical properties of graphite electrodes.

2. Selection of a graphite plate electrode should not be based on the power output but also the cost of the material.

3. The greatest power density was observed for the POCO3 material. The trend for increasing electricity generation was as follows: $\mathrm{POCO} 3>$ G347 > HK06.

4. Microbial analysis showed that the dominant populations are dependent on the graphite characteristics.

5. Selecting electrodes for optimum electricity generation is important in the development of laboratory scale and full-scale MFCs

Further suggested experimental work should consider the following:

1. Perform similar studies in continuous flow MFCs.

2. Further comparison of the graphite plate electrodes using wastewater or substrates from full-scale waste production facilities.

3. Considering other components including different types of cathodes for cost and performance comparison.

4. Assess the scalability of graphite plate electrodes for pilot and full-scale applications.

\section{Acknowledgements}

Financial support for this work was provided by the Natural Sciences and Engineering Research of Canada (NSERC), Ontario Ministry of Research and Innovation, the Canada Research Chair program and the University of Windsor.

\section{References}

[1] Aelterman, P., Rabaey, K., Clauwaert, P., et al. (2006) Microbial fuel cells for wastewater treatment. Water Science \& Technology, 54(8), 9-15.

[2] Ahn, Y., Logan, B. E. (2010) Effectiveness of domestic wastewater treatment using microbial fuel cells at ambient and mesophilic temperatures. Bioresource Technology, 101 (2), 469-475. 
[3] Almiron, M.A, Roset, M.S, Sanjuan, N. (2013) The aggregation of Brucella abortus occurs under microaerobic conditions and promotes desiccation tolerance and biofilm formation. Open Microbiology Journal 7: 87-91.

[4] American Public Health Association (APHA) (2005) Standard methods for the examination of water and wastewater. American Public Health Association, American Water Works Association, and Water Pollution Control Federation. 21 ${ }^{\text {st }}$ edition, Washington, D.C.

[5] Bond D.R and Lovley D.R (2003) Electricity production by Geobacter sulfurreducens attached to electrodes. Applied Environmental Microbiology, 69 (3): 1548-1555

[6] Cha, J., Kim, C., Choi, S., Lee, G., Chen, G., Lee, T. (2009) Evaluation of microbial fuel cell coupled with aeration chamber and bio-cathode for organic matter and nitrogen removal from synthetic domestic wastewater. Water Science and Technology, 60(6), 1409-1418.

[7] Chaganti, S.R., Lalman, J.A., Heath, D.D. (2012) 16S rRNA gene based analysis of the microbial diversity and hydrogen production in three mixed anaerobic cultures. International Journal of Hydrogen Energy, 37(11), 9002-9017.

[8] Cheng, S., Liu, H., Logan, B.E. (2006) Increased performance of single-chamber microbial fuel cells using an improved cathode structure. Electrochemistry Communications, 8 (3), 489-494.

[9] Chew, J., Zilm, P.S, Fus,s J.M., Gully N.J. (2012) A proteomic investigation of Fusobacterium nucleatum alkaline-induced biofilms. BMC Microbiology 12:189.

[10] Du, Z., Li, H., Gu, T. (2007) A state of the art review on microbial fuel cells: a promising technology for wastewater treatment and bioenergy. Biotechnology Advances, 25(5), 464-482.

[11] Franks, A.E., Nevin, K. (2010) Microbial fuel cells, a current review. Energies, 3, 899-919.

[12] Kargi, F., Eker, S. (2009) High power generation with simultaneous COD removal using a circulating column microbial fuel cell. Journal of Chemical Technology and Biotechnology, 84(7), 961-965.

[13] Liu, H., Cheng, S., Logan, B.E. (2005) Production of electricity from acetate or butyrate using a single-chamber microbial fuel cell. Environmental Science and Technology, 39(2), 658-662.

[14] Liu, H., Logan, B.E. (2004) Electricity generation using an air-cathode single chamber microbial fuel cell in the presence and absence of a proton exchange membrane. Environmental Science and Technology, 38(14), 4040-4046.

[15] Logan, B.E. (2008) Microbial Fuel Cells. New York: John Wiley \& Sons.

[16] Logan, B.E. (2012) Essential data and techniques for conducting microbial fuel cell and other types of bioelectrochemical system experiments. ChemSusChem, 5 (6), 988-994.

[17] Logan, B.E., Regan, J.M. (2006) Electricity-producing bacterial communities in microbial fuel cells. Trends in Microbiology, 14(12), 512-518.

[18] Lovley, D.R., Ueki, T., Zhang, T., Malvankar, N.S., Shrestha, P.M., Flanagan, K.A., Aklujkar, M., Butler, J.E., Giloteaux, L., Rotaru, A.E., Holmes, D.E., Franks, A.E., Orellana, R., Risso C., Nevin, K.P. (2011) Geobacter: The microbe electric's physiology, ecology, and practical applications. Advance Microbial Physiol. 59: 1-100.

[19] Rabaey, K., Rozendal, R.A. (2010) Microbial electrosynthesis-revisiting the electrical route for microbial production. Nature Reviews Microbiology, 8(10), 706-716. 
30 Wudneh Ayele Shewa et al.

[20] Rabaey, K., Verstraete, W. (2005) Microbial fuel cells: novel biotechnology for energy generation. Trends in Biotechnology, 23(6), 291-298.

[21] Rahimnejad, M., Ghoreyshi, A.A., Najafpour, G., Jafary, T. (2011) Power generation from organic substrate in batch and continuous flow microbial fuel cell operations. Applied Energy, 88(11), 3999-4004.

[22] Ringeisen, B.R., Henderson, E., Wu, P.K., Pietron, P., Ray, R., Little, B., Biffinger, J.C., Jones-Meehan, J.M. (2006) High power density from a miniature microbial fuel cell using Shewanella oneidensis DSP10. Environmental Science \& Technology, 40(8), 2629-2634.

[23] Sun, Y., Wei, J., Liang, P., et al. (2011) Electricity generation and microbial community changes in microbial fuel cells packed with different anodic materials. Bioresource Technology, 102(23), 10886-10891.

[24] Varmuza, K., Filzmoser, P. (2009) Introduction to multivariate statistical analysis in chemometrics. Florida: CRC press.

[25] Virdis, B., Rabaey, K., Yuan, Z., et al. (2008) Microbial fuel cells for simultaneous carbon and nitrogen removal. Water Research, 42(12), 3013-3024.

[26] Wei, J., Liang, P., Huang, X. (2011) Recent progress in electrodes for microbial fuel cells. Bioresource Technology, 102(20), 9335-9344.

[27] Wiegant, W. M., Lettinga, G. (1985) Thermophilic anaerobic digestion of sugars in upflow anaerobic sludge blanket reactors. Biotechnology and Bioengineering, 27(11), 1603-1607.

\section{Biographies}

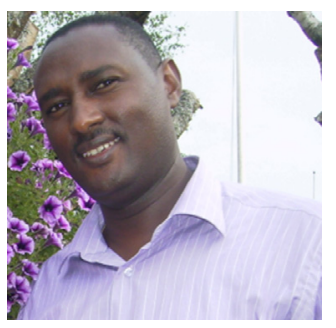

Wudneh Shewa earned an undergraduate degree in sanitary engineering from Arba Minch University in Ethiopia and a master's degree in environmental engineering from the Indian Institute of Technology (IIT-Roorkee).

$\mathrm{He}$ is currently a fourth year $\mathrm{PhD}$ student enrolled in the Environmental Engineering program at the University of Windsor. Prior to attending the University of Windsor, Wudneh was teaching water and waste water engineering courses for more than 10 years in Ethiopia at Arba Minch University and Hawassa University. He has also worked for a European Union funded research project called ROSA (Resource-Oriented Sanitation concepts for peri-urban 
areas in Africa) as a Local Project Coordinator. The ROSA project received the 2011 IWA Project Innovation Award.

Wudneh's research interests include microbial fuel cell, Bio-hydrogen production, wastewater treatment and resources oriented sanitation.

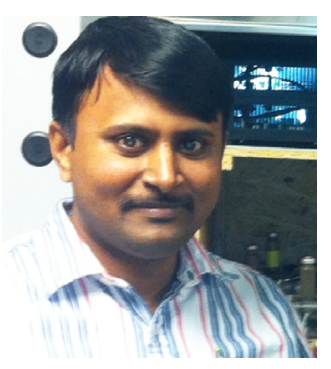

Dr. Subba Rao Chaganti earned his Ph.D degree (Biotechnology) from Jawaharlal Nehru Technological University, India. He conducted his research studies for 5 years in Indian Institute of Chemical Technology with CSIR Senior Research Fellowship and several other Indian research council fellowships. From $>5$ years he is conducting research at the University of Windsor, Canada. Dr. Chaganti taught several undergraduate courses related to Microbiology, Biochemistry and Molecular biology in India and Canada. He has published $>50$ peer reviewed papers in international journals a text book and four book chapters. His articles are well citied by international scientific community $(\mathrm{CI}=>850)$, with $\mathrm{h}$ index 17 . His research contributions have been recognized as a prestigious Young Scientist Award by Andhra Pradesh Academy of Sciences, American Society of Microbiology (ASM) Young Ambassador to Canada and Ambassador to ORCID. He secured several national and International fellowships in different stages of his research career such as CSIR Senior Research Fellowship, Australian Endeavor Research Fellowship, Ontario Ministry of Research and Innovation Fellowship, NSERC Visiting Fellowship. From past 5 years he is serving as a reviewer for $>20$ International journals and editorial board member to several Journals. He severed as organized committee member to international conferences and also he organized the conferences. He established the ASM Bio-resource center and ASM student chapter in Canada. Over his 11 years of research career he trained many undergraduate and graduate students.

Dr. Chaganti research interest includes wide area of Microbial Genomics and metabolomics related to environmental and biotechnology applications. 
32 Wudneh Ayele Shewa et al.

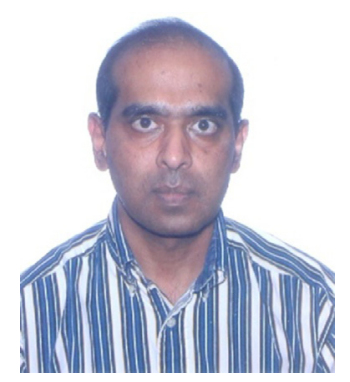

Dr. Lalman's primary research areas of interest at the University of Windsor are focused on developing fermentation processes to produce biofuels and chemicals from agriculture products and residues. He is also involved in the development of microbial fuel cells, producing biodiesel using algae and using photocatalysts to produce feedstock chemicals.

Dr. Lalman has undergraduate degrees in chemistry and chemical engineering. His MASc and $\mathrm{PhD}$ degrees are in chemical engineering and environmental engineering, respectively. He began his academic career after completing doctoral studies at the University of Toronto in 2000. From 1983 to 1995, while employed in consulting engineering, he worked on projects in the fine chemicals, petroleum, food processing, pulp and paper and automotive sectors. 